\title{
ARCHES DUNHUANG: HERITAGE INVENTORY SYSTEM FOR CONSERVATION OF GROTTO RESOURCES ON THE GANSU SECTION OF THE SILK ROAD IN CHINA
}

\author{
Xiaowei Wang ${ }^{1}$, Yipu Gong ${ }^{1 *}$, David Myers ${ }^{2}$, Shunren Wang ${ }^{1}$ \\ ${ }^{1}$ Dunhuang Academy, Dunhuang, Gansu, China - (xiaoweiw324, gongyipu, srwangdh)@ hotmail.com \\ ${ }^{2}$ Getty Conservation Institute, Los Angeles, California, USA - DMyers@getty.edu
}

KEY WORDS: Arches, Heritage Inventory, Semantic Data Modelling, Grottoes, Silk Road.

\begin{abstract}
:
The cultural heritage of the Buddhist grottoes on the Gansu section of the Silk Road in China has important historical, cultural and artistic values. In order to better protect these precious cultural sites including through facilitating ongoing assessment of their condition, the Dunhuang Academy has created a pilot inventory based on the Arches open-source software platform. This paper first briefly introduces the most important grottoes and the representative caves in Gansu province. It then, in view of the diversity of the grotto architecture layout, describes the Arches semantic graph data modelling technology and how the flexibility of Arches Designer was used to design the resource models, which not only meet data management needs, but also ensure data interoperability and longevity through incorporation of the CIDOC-CRM ontology. In addition, through design of the grottoes map plugin and resource components within Arches, the simple interaction and intuitive visualization of grottoes information was achieved. The Dunhuang Academy's deployment of Arches will serve the need for grottoes data management and provide support for the establishment of a more scientific and effective protection and management system for the grottoes on the Silk Road in Gansu province. It is hoped that this project will demonstrate the suitability of the Arches platform to support the management of other grotto sites outside of Gansu province, as well as for heritage management elsewhere in China.
\end{abstract}

\section{INTRODUCTION}

Along the Gansu section of the Silk Road in China, there are 127 Buddhist grottoes, dating from the Sixteen Kingdoms to the Northern Wei, Sui, Tang, Song, Yuan, Ming and other dynasties. Among these sites, there are World Heritage Sites such as Mogao Caves, Maijishan Grottoes and Bingling Cave-Temple, which are large in scale, exquisite in murals and sculptures, and relatively standardized in conservation and management. There also are many small and medium-sized grottoes. Although they have certain values, due to the remoteness of location and the smaller number of caves, they have not been effectively protected. In order to fully understand the condition of the grottoes on the Gansu section of the Silk Road and further strengthen the conservation of this precious historical heritage, in 2018 experts from the Getty Conservation Institute (GCI) of the United States and the Dunhuang Academy of China jointly investigated the conservation and management status of these grottoes. In 2020, China has also launched a special survey of grottoes at the national level. Through this work, essential information about the location, quantity, content, heritage value, and conservation condition of grottoes in Gansu Province has been obtained.

Taking into account the different scales, the wide geographical distribution, and the unbalanced management level of these grottoes, it is necessary to establish a heritage inventory system to unify management of the essential data, and provide support for the establishment of a more scientific and effective conservation and management system for the grottoes on the Silk Road in the province. Using information technology to integrate the grottoes of Gansu into a unified inventory framework for management will also contribute to the comparative research of different grottoes, and promote standardized records of heritage integrity and condition, as well as heritage value recognition. In addition, part of the inventory content can also be accessed by the public to enhance its awareness of the grottoes' heritage values.

Heritage inventories are ongoing, authoritative records identifying and describing the essential aspects of significant as well as potentially significant heritage resources. Inventories are vital tools for heritage protection, including in cases of armed conflicts, natural disasters, as well as global warming and urbanization which have become more and more pronounced in recent years. International institutions such as UNESCO and ICOMOS, as well as numerous national and regional heritage authorities around the world have all recognized the importance of inventories to heritage management (Myers, 2016).

In response to the critical and common challenges of cultural heritage organizations around the world around creating and maintaining modern inventory systems, the GCI and World Monuments Fund (WMF) co-developed the Arches software platform. In developing Arches, the GCI and WMF sought to make an inventory system available to heritage organizations that is built with the latest technologies and that is economical through an open-source approach (Myers et al., 2016). Arches incorporates internationally adopted standards for heritage inventory, semantic data modelling, and software security. Arches also realizes interactive visual modelling for all types of heritage resources, which can effectively improve the level of heritage data management and facilitate data exchange and longevity in spite of advances in technology. Up to now, numerous heritage inventories have been deployed using Arches. These implementations range in scale from the multinational, national, regional, and local, including the Endangered Archaeology in the Middle East and North Africa (EAMENA) project which spans a 20 country region (Zerbini 2018), national inventories for Jamaica, Barbados, Bhutan (Williams, 2016), Jersey, and the Isle of Man, as well as the cities of Los Angeles (City of Los Angeles, Office of Historic Resources) and Lincoln,

\footnotetext{
* Corresponding author
} 
UK. ${ }^{1}$ The Dunhuang Academy has chosen to build its grottoes inventory system utilizing the Arches open-source platform, which will reduce the workload of system development, improve the system's openness and provide for compatibility with international standards.

This paper will give an overview of the creation of our grottoes inventory system. First, it briefly introduces the most important grottoes and the representative caves in Gansu Province. Then, the application of international standards and some key technologies in the inventory system are introduced, and finally, the current system deployment results are shown. It concludes by discussing the system's further customization plan and application prospects.

\section{RESEARCH OBJECTIVES}

Gansu Province is located in Northwest China. The terrain is long and narrow, and slopes from southwest to northeast, with complex and diverse landforms, including mountains, plateaus, plains, river valleys, and deserts (including the Gobi). The climate types from south to north include subtropical monsoon climate, temperate monsoon climate, temperate continental arid climate and plateau mountain climate (Gansu Provincial Government, 2016).

Gansu provided the only way to the West on the ancient Silk Road, serving as the bridge connecting Eastern and Western civilizations. For thousands of years, with the prosperity and decline of the Silk Road, a large amount of cultural heritage has been preserved in Gansu. Among them, the grotto sites are large in number and scale, with murals and sculptures representing different historical periods, having rich and extremely significant content. These sites constitute a relatively complete history of Buddhist grotto art. Therefore, Gansu Province is also known as the "Hometown of Chinese Grotto Art".

At present, there are 127 grotto sites officially listed at or above county-level significance: 18 national level sites (including 3 World Heritage Sites), 12 provincial level sites, and 97 county or municipal level sites. ${ }^{2}$ There are also many grotto sites without an official designation in Gansu. All these grottoes are widely distributed, with unbalanced scale and artistic values.

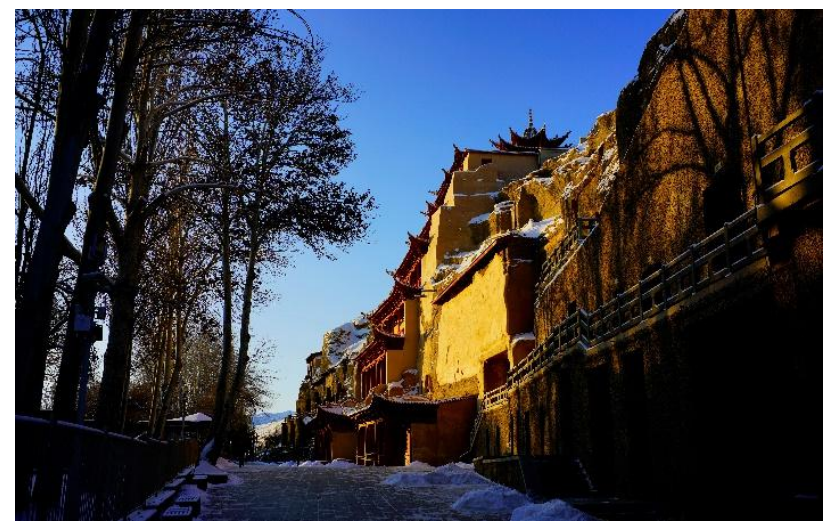

Figure 1. Mogao Caves

1 For an updated listing of featured implementations of the Arches platform, see "Implementations of Arches" at: https://www.archesproject.org/implementations-of-arches/

2 The data comes from the DA-GCI collaboration project: Guidelines for Conservation and Management of Gansu Province Grotto Sites
Among them, the World Heritage Site Mogao Caves (Figure 1) is well known all over the world because of the largest existing scale, the longest historical timespan (from the 4th to the 14th centuries), the richest content, and the most integrated preservation. Grottoes at Mogao were first constructed in $366 \mathrm{AD}$ and represent a great achievement of Buddhist art. Seven hundred thirty-five caves are presently preserved, 492 of which have murals and statues, housing about 45,000 square meters of murals and more than 2,000 painted sculptures. From the Song dynasty Cave, 61 depicts the celebrated landscape of Mount Wutai. It is an early example of artistic Chinese cartography, where nothing has been left out - mountains, rivers, cities, temples, roads and caravans are all depicted.

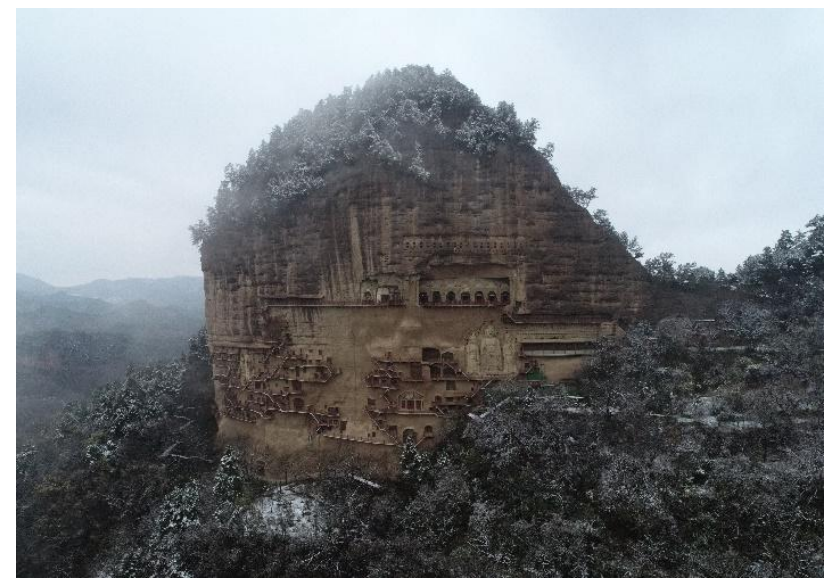

Figure 2. Maijishan Grottoes

Unlike Mogao Caves, located in the Gobi Desert, the Maijishan Grottoes and Bingling Cave-Temple are an important part of the Silk Roads: The Routes Network of Chang'an-Tianshan Corridor World Heritage Site, which have different geographical features. Maijishan Grottoes (Figure 2) is located on a solitary peak cliff in the Xiaolongshan Botanical Garden in Tianshui City, Gansu Province. It was first constructed between $384 \mathrm{AD}$ and 417AD. Two hundred twenty-one caves are presently preserved and have 10,632 clay sculptures and more than 1,300 square meters of murals. It is known for its exquisite clay sculpture art, and referred to as the "Oriental Sculpture Art Exhibition Hall".

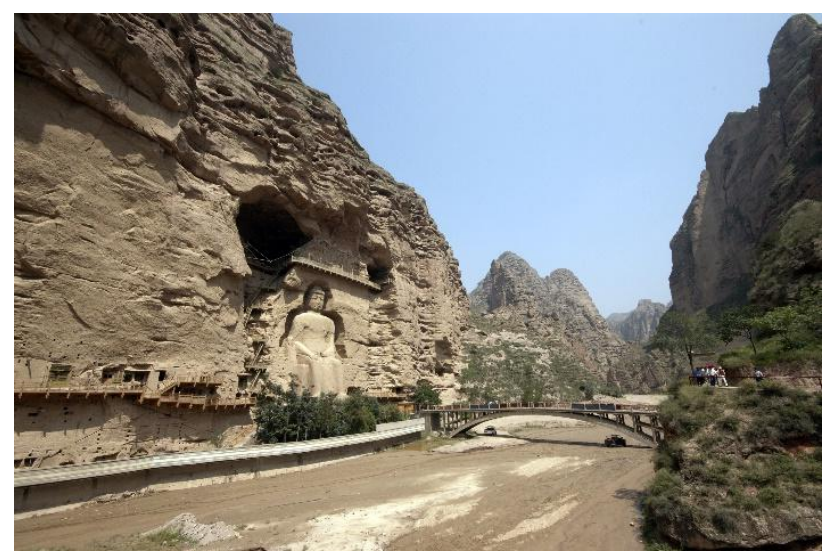

Figure 3. The Bingling Cave-Temple

The Bingling Cave-Temple (Figure 3) is located on a cliff along the Yellow River Reservoir. It was first constructed in the early years of the Western Jin Dynasty (about the 3rd century AD). 
One hundred eighty-three caves/niches are presently preserved and have 694 stone sculptures, 82 clay sculptures and approximately 900 square meters of murals. Among them, there is an inscription on the north wall of Cave 169, which records that the statue in the niche was built in the first year of Jianhong (420 AD). This is the earliest surviving statue inscription in a cave in China, providing that it holds important historical and academic values.

At present, the World Heritage Sites Mogao Caves, Maijishan Grottoes, Bingling Cave-Temple, as well as the national level sites Yulin Grottoes, West Thousand Buddha Caves, and North Grottoes are all under the unified management of the Dunhuang Academy. Over the years, the Dunhuang Academy has carried out a large number of works with the help of advanced science and technology, such as caves condition assessment, archaeological surveying and mapping, environmental monitoring, deterioration prevention, and digitization of heritage resources through cooperation with professional institutions around the world. These works have enabled the effective preservation of the key attributes of the heritage and at the same time formed a complete conservation archive. At the 34th session of the World Heritage Committee held in Brazil in 2010, management of Mogao Caves was recognized as a best practice on effective conservation and sustainable tourism management.

However, we should also note that, in addition to the six sites mentioned above, most of the grottoes in Gansu province have not been effectively conserved due to their small scale, remote location, and low professional capacity of the team managing them. These sites are still facing the crisis of destruction brought by rapid population growth, urbanization, and farmland development activities. Therefore, we decided to build a province-wide grottoes inventory system based on Arches, to manage the essential information of the grottoes, and to establish a dynamic database for recording regular assessments of their conditions. This database is intended to lay the foundation for the standardized management, preventive protection and sustainable development of the grottoes of Gansu province.

\section{PROJECT METHODOLOGY}

\subsection{Semantic Graph Data Modelling}

Heritage inventories are used to document essential information about cultural heritage in order to protect it for the future. For the grottoes, a clear and complete data framework design that facilitates the long-term preservation of inventory data is a key factor for the success of the project. Due to the diversity of the caves' architecture, layout, and heritage elements, it is necessary to ensure that the design of a data framework meets the challenging data management requirements of these unique grottoes. At the same time, the changing conditions and deterioration of the murals in the grottoes needs to be regularly monitored. Therefore, it is also necessary for the system to be able to track deterioration through regular updates to the assessment data. Cultural heritage, of course, should be preserved for the long-term, and a heritage inventory should be a faithful witness to the evolution, integrity, and changes in the conservation status of cultural heritage. Thus, the data in inventories needs to be protected for the future and not susceptible to data loss or corruption due to technological or software upgrades or other changes.
The use of semantic graph data modelling technology in Arches meets the above requirements. First, the data models are constructed based on a graph data structure instead of a twodimensional table structure used in a traditional relational database, which greatly improves the system's ability to model entity relationships and can flexibly represent the complex data requirements such as those for the grottoes. Second, Arches offers a standards- and semantic-based data architecture using the CIDOC Conceptual Reference Model (CRM) (ISO, 2014) to structure relationships between data fields. The default data structure of Arches was also informed by the draft CIDOC International Core Data Standard for Archaeological and Architectural Heritage (CIDOC Archaeological Sites Working Group, 2014). Moreover, data in Arches are appended with an additional machine-readable meaning, so that a computer can parse and interpret the data and this, in turn, promotes data exchange and ensures data longevity. Finally, the most important advantage of Arches is that it integrates the above technologies and standards in a data management system for the first time, providing flexible and convenient resource model design tools that allow data managers to construct graph data models and define the entity relationships by a click on the web interface, which greatly improves the convenience of building a heritage inventory.

The semantic graph data modelling process in Arches includes two parts: constructing the graph data structure and defining semantic metadata. In Arches, the graph data model is called a resource model and is composed of nodes and edges. A node (similar to a data field) is the smallest unit of the resource model. Different nodes are linked by edges, which define the relationships between the nodes to form a network. Each resource model specifies one node as the top node. The top node is the root node of the entire resource model and defines what the resource model is describing as a whole. The top node is also where the resource model information is stored, such as model name, subtitle, status, related resource models, description and where appearance is specified. In addition, if the model needs to define semantic metadata, the corresponding ontology (the CIDOC CRM) and CRM Class must be selected for the top node. Once the top node is defined, the remaining nodes in the resource model are used to define resource or attribute information. The key components of each node include node name and data type, and the value of the node is used to record actual business data. Because we are using a semantic ontology, as defined by the top node, the rest of the nodes are also required to define a corresponding CRM Class and also specify a CRM Property for the edge between the node and the node upstream from it, thus defining the relationship between the two nodes. Node data types that are specific to Arches include 'semantic,' 'concept,' and 'concept-list'. Among these, a node with the 'semantic' data type selected is only used to define semantic metadata and does not record an actual value or business data. The 'concept' and 'concept-list' data types indicate that the data field is selected from custom concept collections which are created in the Arches Reference Data Manager (RDM) from controlled vocabularies or thesauri. By using the data types 'concept' and 'concept-list' and hence controlled vocabularies there is more control over what is entered in to each data field and at the same time data searching is improved.

Figure 4 uses a condition assessment branch as an example to illustrate the semantic graph data modelling process. The top node 'Cave Element' in the figure represents any heritage element in the cave, which can be a wall with a mural or a sculpture. The CRM Class of this node is defined as E24 
(Physical Man-Made Thing) and the data type is defined as 'Concept,' which means that the value of this data field is selected from a concept list of cave elements and these are predefined in the Arches RDM. The adjacent node of the 'Cave Element' node is 'Condition Assessment.' The CRM Class of this node is defined as E14 (Condition Assessment) and the data type is defined as 'semantic.' The edge between node 'Cave Element' and node 'Condition Assessment' is defined by the CRM Property as P41i (was assessed by). This then constitutes a complete semantic expression in which 'Physical Man-Made Thing' was assessed by 'Condition Assessment.' Similar semantic patterns are defined for the remaining nodes, which can be viewed from the CRM definitions. In Figure 4 'Condition Assessment' is defined by 'Condition State' and 'Condition State' has time-span, type, image, and description attributes. From the perspective of the Arches graph data model Designer, the four nodes of 'Condition Assessed Date,' 'Deterioration Type,' 'Deterioration Description' and 'Deterioration Image' together comprise the 'Condition State' node group. In actual business scenarios, a deterioration condition assessment can use the above branch structure to record information. And for a certain mural or statue, the condition assessment work is often carried out periodically. In Arches, the nodes in a node group, also known as "a card," can be configured to allow multiple values or instances of the card In this way, the data for multiple deterioration assessment activities can be recorded.

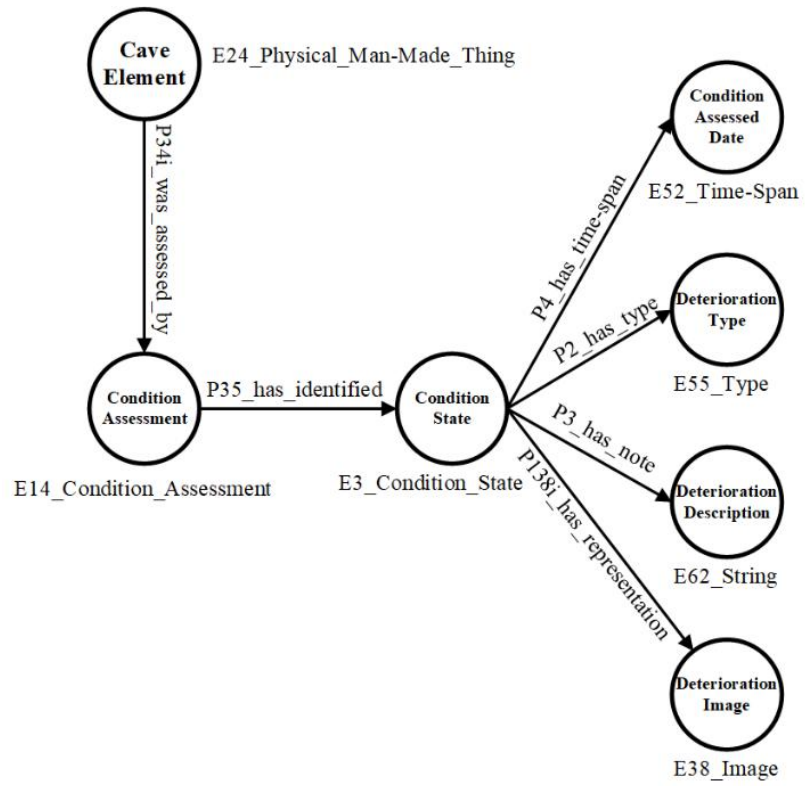

Figure 4. Example of condition assessment branch

Based on this approach, Arches realizes the modelling of realworld physical resources and complex business logic. At the same time, the data is structured to be self-describing and machine-readable so that data can be independent of any particular software application and be exchanged across systems, thereby facilitating longevity and storage for the long term.

\subsection{Standards and Tools}

The Arches platform provides semantic modelling tools enabling the design and implementation of data models based on ontologies such as the CIDOC-CRM, LinkedArt, and other standards. Arches also provides sophisticated geospatial data management capabilities such as input, editing, analysis, presentation and search of spatial data. Arches integrates with GIS applications and web-based mapping services and supports geospatial data standards such as geojson, vector tiles, and proprietary services such as esri feature services.

The grottoes in Gansu are geographically dispersed. One advantage of using Arches to manage the grottoes is that it can realize intuitive management of the geographic locations of different grottoes based on its built-in geographic location services. At the same time, Arches support for multiple geospatial web services make it possible to migrate data between different GIS services.

\section{RESULTS}

\subsection{Resource Models}

In order to meet the essential data management requirements of the grottoes in Gansu Province-we constructed several resource models based on the semantic graph data modelling technology and the Arches Designer tool. To date these include the following resource models: Heritage Site, Cave, Condition Assessment, Conservation Project, Organization, People and Information Resource, as shown in Table 1. These models not only help realize the comprehensive management of the essential information of the grottoes, but also realize the semantic modelling based on the CIDOC-CRM, so that computers can automatically parse the data meaning, and facilitate data exchange and longevity.

\begin{tabular}{|c|c|}
\hline $\begin{array}{c}\text { Resource } \\
\text { Model Name }\end{array}$ & Resource Model Nodes \\
\hline Heritage Site & $\begin{array}{l}\text { Name, Description, Historical Timespan, } \\
\text { Heritage Elements, Address \& Location, } \\
\text { Geographical Coordinates, Conservation } \\
\text { Level, World Cultural Heritage(Y/N), } \\
\text { Property \& Buffer Zone Spatial Geometry, } \\
\text { Value Assessment, Reference Image, } \\
\text { Management Agency, External Identifier }\end{array}$ \\
\hline Cave & $\begin{array}{l}\text { Related Heritage Site, Name, Description, } \\
\text { Location, Construction/Rebuild Period, Cave } \\
\text { Elements, Mapping Data, Value Assessment, } \\
\text { Risk Level Assessment, Reference Image }\end{array}$ \\
\hline $\begin{array}{l}\text { Condition } \\
\text { Assessment }\end{array}$ & $\begin{array}{l}\text { Related Cave, Cave Element, Condition } \\
\text { State, Condition Assessment Date, } \\
\text { Deterioration Type, Deterioration } \\
\text { Description, Deterioration Image }\end{array}$ \\
\hline $\begin{array}{l}\text { Conservation } \\
\text { Project }\end{array}$ & $\begin{array}{l}\text { Name, Related Resource, Type, Description, } \\
\text { Activity Phase, Content, Result, Related } \\
\text { Agency, Key Personnel }\end{array}$ \\
\hline Organization & $\begin{array}{l}\text { Name, Description, Address, Legal Person, } \\
\text { Reference Image, External Identifier }\end{array}$ \\
\hline People & $\begin{array}{l}\text { Name, Gender, Nationality, Date of Birth, } \\
\text { Photo, Phone, Email, Address, Resume }\end{array}$ \\
\hline $\begin{array}{l}\text { Information } \\
\text { Resource }\end{array}$ & $\begin{array}{l}\text { Title, Type, Description, Information Carrier, } \\
\text { Data Format, Language Type, Publication } \\
\text { Date, Copyright Description }\end{array}$ \\
\hline
\end{tabular}

Table 1. Grottoes Resource Models

\subsection{Grottoes Map Plugin}

In order to better present the spatial relationship of different grottoes, as well as realize the visual presentation and global management based on spatial location, the grottoes map plugin was designed and implemented based on the spatial data management capabilities of Arches. In the plugin, the grottoes 
basic data view and the real-time monitoring data view are realized respectively.

The grottoes basic data view is shown as Figure 5. The grottoes are marked on the map with different colors according to the protection level. All the markers employ interactive design, allowing users to click to open a popup and to show the basic information of the grottoes, as well as providing the resource report URL corresponding to the grottoes to further view detailed information.

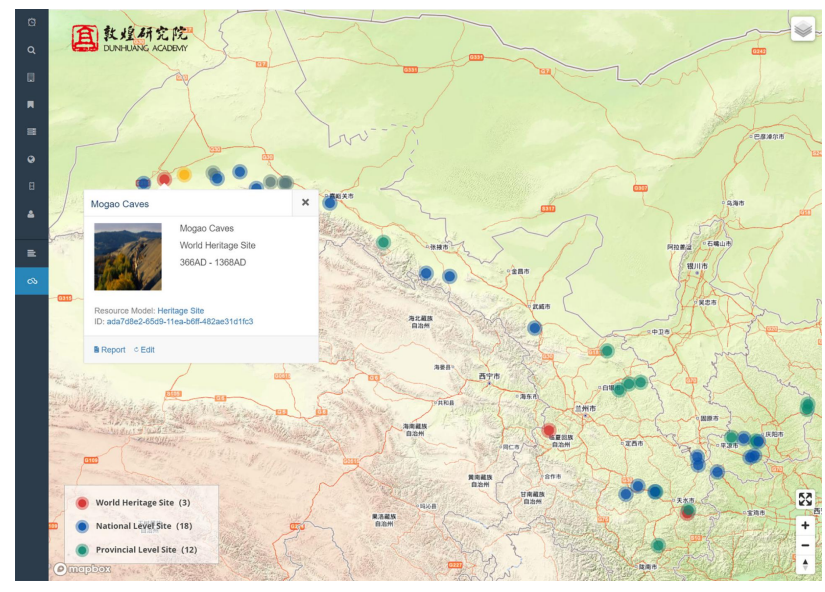

Figure 5. The grottoes basic data view Base Map Source: (C) Tianditu

Using the map layer management menu, the map view can be switched to the real-time monitoring data view, as shown in Figure 6 . The real-time weather conditions and the number of tourists visiting are visually presented on the map. The weather data comes from the local meteorological department, and the information about the number of tourist visitors comes from the ticketing system of each grotto. Of course, in this view, important data of each grotto can also be continuously updated, providing platform support for the global visual management of the grottoes in Gansu.

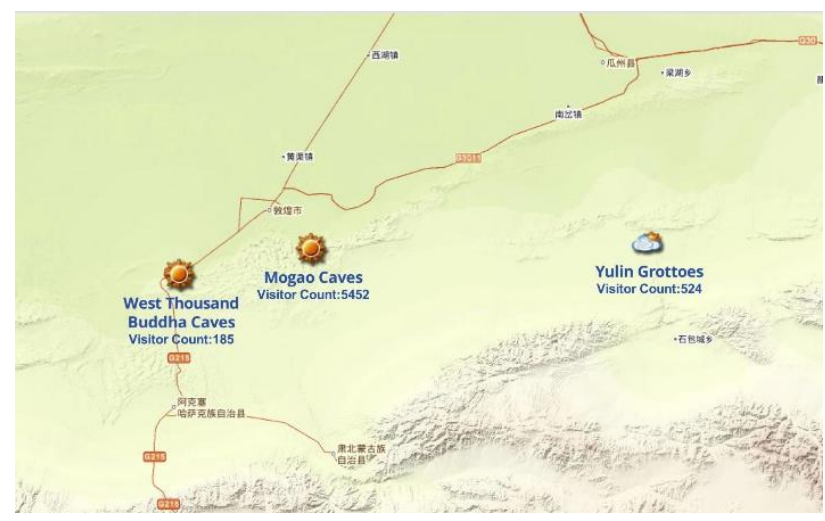

Figure 6. The real-time monitoring data view Base Map Source: (C) Tianditu

Based on the grottoes map plugin, managers can intuitively view the basic data and real-time monitoring data of grottoes in Gansu. For meteorological disasters, such as flooding, and other risk events, they can formulate response measures, and use Arches to record assessments of impacts after the event. The public can also check the grottoes status at any time based on this plugin, and adjust their travel itinerary accordingly.

\subsection{Resource Components Design}

When constructing the inventory, a series of custom components were designed based on the Arches development framework to support the data visualization and interaction requirements. For the grottoes inventory data, the cave vertical location has particularity. The traditional method is to indirectly describe the vertical location of the cave with text, including the content such as distribution of surrounding caves. In order to express the vertical location of the cave more intuitively, in our project we take advantage of the flexibility of the Arches components, through defining a new data type and widget. In conjunction with a traditional map view identifying grotto horizontal location, the Dunhuang Academy has developed a new data type and widget to support identifying cave vertical location through annotation of a panoramic cliff face elevation image showing locations of the entrances of a number of grottoes. It is anticipated that this new data type and widget could potentially be applied to support identifying the vertical location of other heritage typologies, such as rock art and perhaps other site types constructed into cliff faces or other types of steep terrain. At the same time, we redesigned the resource report templates to support display of cave vertical location on the cliff face elevation image, as shown in Figure 7. The advantage of this is also reflected in the presentation of the correlation between the Heritage Site resources and the Cave resources. The traditional way is to use the hypertext link to list all the caves belonging to a particular grottoes site, such as Mogao. Our project uses the location annotation data in the Cave resource model. When opening a Heritage Site resource report, all caves belonging to the grottoes site can be presented on the elevation and realized interactively to access the corresponding cave report.

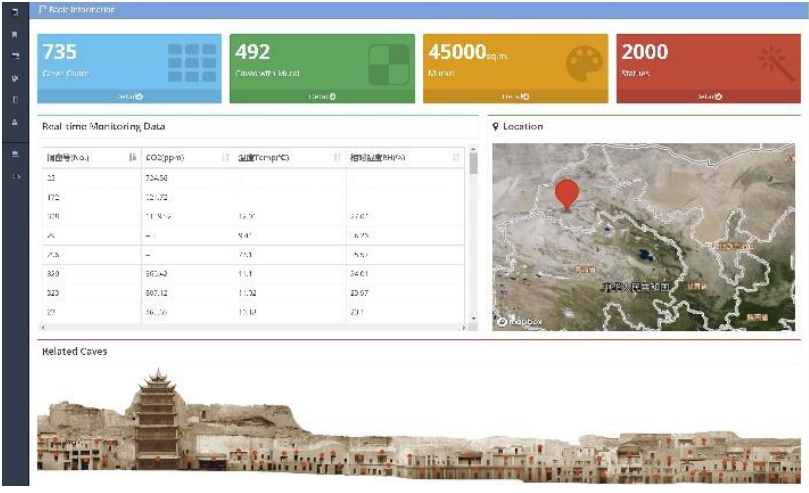

Figure 7. Heritage Site resource template

The Dunhuang Academy also integrated real-time data sources such as cave microenvironment monitoring (including air temperature, relative humidity, carbon dioxide concentrations, etc.) in the Heritage Site resource templates (also shown in Figure 7). Studies have shown that salt accumulation and deliquescence are the main reasons for the ongoing deterioration of the murals, evidenced in many of the Mogao caves (Agnew et al., 2010). Hygroscopic salts will deliquesce as atmospheric humidity rises and recrystallize as it falls. Therefore, it is necessary to monitor environmental factors such as the relative humidity in the caves. When the relative humidity exceeds a certain threshold, the tourism opening strategy should be adjusted and certain environmental control measures should be taken to reduce the cave relative humidity. On the other hand, the cave space is usually narrow. A large number of tourists entering a cave will cause the carbon dioxide concentration to exceed the established standard, which will affect the health of 
the visitors. Therefore, it is also important to monitor and control the carbon dioxide concentration in the cave. These measures are the key means for the preventive conservation of the grottoes and for visitor safety. The integration of microenvironment monitoring data sources with the Dunhuang Academy's Arches inventory can facilitate the DA's conservation and management work and enhance its risk management.

In addition, the Heritage Site resource model realizes the visual management of the property and buffer zone boundaries as spatial geometries of each grottoes site, as shown in Figure 8.

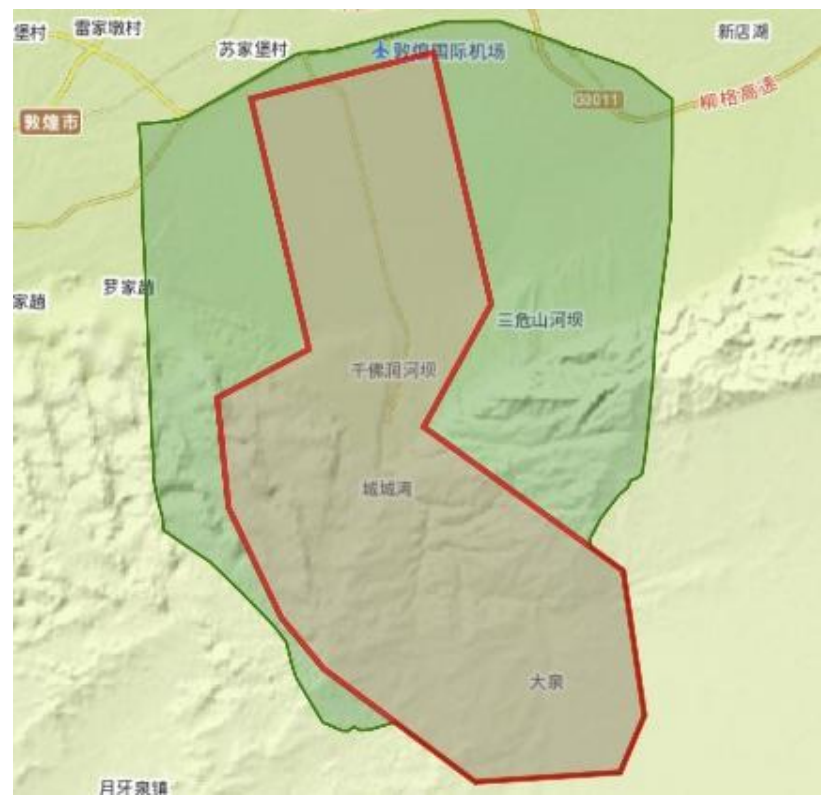

Figure 8. Grottoes Property \& Buffer Zone Spatial Geometry Base Map Source: (C) Tianditu

In view of the large number and complex architecture layout of the caves, we have also redesigned the report template of the Cave resource model, integrating the cave panorama image, as shown in Figure 9. System users can drag their mouse to visually view the cave element in $360^{\circ}$, which is helpful to understand the cave layout.

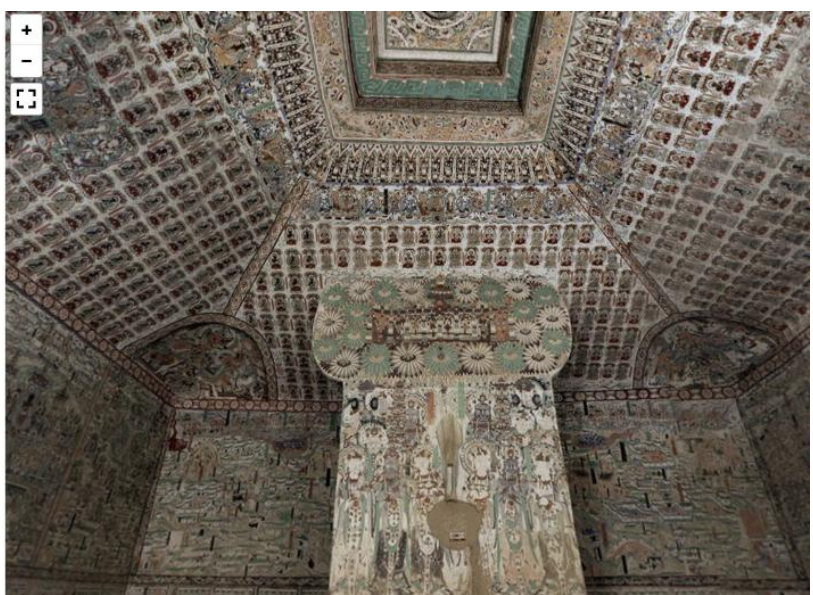

Figure 9. Cave Panorama View Image Source: (C) Digital Dunhuang Project

\section{CONCLUSIONS}

The cultural heritage of the grottoes on the Gansu section of the Silk Road in China has important historical, cultural and artistic values. In order to better protect these precious heritage sites, the Dunhuang Academy has created a pilot grottoes inventory based on Arches, realizing the unified management of the essential information of the grottoes.

During the construction of the inventory, in view of the diversity of the cave architecture layout, the Arches semantic graph data modelling technology and the flexibility of Arches Designer were used to design the resource models, which not only meet data management needs, but also ensure data interoperability and longevity. In addition, through designing the grottoes map plugin and resource components, the simple interaction and intuitive visualization of grottoes information was achieved.

Based on the work of the Dunhuang Academy to date, the next step will be to input the primary information of the main grottoes into the system, and actively promote and apply it in each heritage site, further optimize the system design according to the actual needs of each grotto, and focus on the data analysis and visualization. If the pilot project is successful, the Dunhuang Academy will extend the system to all 127 grottoes in Gansu. According to the currently designed resource models, the system will include the basic information such as site name, geographic location, surveying and mapping data for each grotto, as well as dynamic information such as ongoing assessment data of deterioration condition and conservation project records, and it will contain data types include images, documents, 3D models, etc. Eventually, a dynamic database will be built and will become the basic data source for the protection and management of the grottoes in Gansu Province.

The project contributes to the grottoes data management and provides support for the creation of a more scientific and effective protection and management system for the grottoes on the Silk Road. The Dunhuang Academy has developed a new data type and widget to support identifying cave vertical location through annotation of a panoramic cliff face elevation image showing locations of the entrances of a number of grottoes. It is anticipated that these developments could potentially be applied to support identifying the vertical location of other heritage typologies, such as rock art and perhaps other site types constructed into cliff faces or other types of steep terrain. The Dunhuang Academy's incorporation of real-time data feeds for particular grottoes, such as relative humidity, carbon dioxide, and visitor numbers, is a new development in the use of Arches to date, and offers a range of possibilities to other Arches deployments. It is also hoped that this project can demonstrate the suitability of the Arches platform to support the management of other grotto sites outside of Gansu province, as well as for heritage management elsewhere in China.

\section{ACKNOWLEDGEMENTS}

The authors are grateful to Neville Agnew, Martha Demas, Alison Dalgity and Poming Lin for proofreading the paper. This research was supported by the National Cultural Heritage Administration of China under Project No. 2020ZCK108, and the Cultural Heritage Administration of Gansu under Project No. GWJ201801. The authors would also like to thank the China Dunhuang Grottoes Conservation Research Foundation for funding. 


\section{REFERENCES}

Agnew, N., Maekawa, S., Wei, S., 2010. "Causes and mechanisms of deterioration and damage in Cave 85." Conservation of ancient sites on the Silk Road : proceedings of the second international conference on the conservation of grotto sites 2010, 412-420.

City of Los Angeles, Office of Historic Resources.

"HistoricPlacesLA: the Los Angeles Historic Resources Inventory," http://historicplacesla.org (5 March 2021).

CIDOC Archaeological Sites Working Group. 2014. International Core Data Standard for Archaeological and Architectural Heritage (working draft).

Gansu Provincial Government, 2016. Geography and Landforms of Gansu Province, http://www.gansu.gov.cn/col/col2084/index.html (5 March 2021).

ISO, 2014. Information and documentation - A reference ontology for the interchange of cultural heritage information, ISO 21127:2014. Geneva, Switzerland: International Organization for Standardization https://www.iso.org/standard/57832.html

Myers, D., 2016. "Heritage inventories: promoting effectiveness as a vital tool for sustainable heritage management." Journal of Cultural Heritage Management and Sustainable Development 6(2), 102-112.

https:/www.getty.edu/conservation/our_projects/field_projects/ arches/JCHMSD_2016_Inventory_Effectiveness.pdf

Myers, D., Dalgity, A., Avramides, I., 2016. "The Arches heritage inventory and management system: a platform for the heritage field." Journal of Cultural Heritage Management and Sustainable Development 6(2), 213-224.

https://www.getty.edu/conservation/our_projects/field_projects/ arches/JCHMSD_02_2016_Arches.pdf

Williams, T. D., 2016. "Silk Roads in the Kingdom of Bhutan and the Development of a National Heritage Inventory." Archaeology International 19, 122-123. https://doi.org/10.5334/ai.1918

Zerbini, Andrea. 2018. "Developing a Heritage Database for the Middle East and North Africa". Journal of Field Archaeology 43 (Supplement 1), 9-18. https://doi.org/10.1080/00934690.2018.1514722 